\title{
Algunos construirán con piedra sobre este fundamento y otros con paja Reflexiones teológicas sobre la victoria electoral de la izquierda en EI Salvador
}

\author{
Juan Hernández Pico, S.J., \\ Centro de Reflexión Teológica, \\ San Salvador.
}

1. La fe y los proyectos históricos de izquierda en América Latina

¿Tiene algo que ver con la fe la victoria en El Salvador del candidato presidencial del Frente Farabundo Martí para la Liberación Nacional (FMLN), Mauricio Funes Cartagena? Quienes nos sentimos inclinados a responder afirmativamente debemos cargar antes con la responsabilidad de dar razón de la esperanza que pareció alumbrar en la vida de las mayorías pobres de Centroamérica con la victoria del Frente Sandinista de Liberación Nacional (FSLN) en Nicaragua precisamente hace 30 años, el 19 de julio de 1979. O con la firma de los Acuerdos de Paz en Guatemala el 29 de diciembre de 1996. O con el triunfo del teniente coronel retirado Hugo Chávez Frías en Venezuela en 1998. O con el triunfo del candidato del Partido de los Trabajadores (PT), Luiz Inácio "Lul" a da Silva en octubre de 2002 en Brasil. O con el triunfo del candidato aymara Evo Morales, en diciembre de 2005 en Bolivia. O con el triunfo de Correa en Ecuador en 2009, que supuso la reelección y la aprobación del proyecto de nueva Constitución. Y si queremos ir más lejos, tendríamos también que dar razón de la esperanza que produjo en mucha gente pobre latinoamericana la victoria de la Revolución cubana en 1959 y el triunfo electoral del proyecto de camino hacia el socialismo en libertad, en septiembre de 1970, que llevó a la presidencia a Salvador Allende, derrocado y muerto el 11 de septiembre de 1973 por un golpe militar, que se mantuvo en el poder con costos humanos brutales hasta el referendo de 1988 y la elección presidencial de 1989 ganada por la Coalición del 
Partido Demócrata Cristiano y del Partido Socialista, que ha vencido en cuatro elecciones consecutivas durante 16 años. Todos estos triunfos fueron el sello, revolucionario o electoral, a proyectos políticos cuyo objetivo fundamental era la reducción o incluso la supresión de la miseria y la pobreza de las grandes mayorías y el desarrollo humano de los países donde se produjeron para alcanzar un bienestar digno de personas humanas. Ocurre que estos proyectos han tenido trayectorias profundamente diferentes.

\section{La revolución cubana}

La revolución cubana, gestada en plena Guerra Fría entre los Estados Unidos de Norteamérica y la Unión Soviética, nunca pudo ni tampoco quiso desembro1larse de esa rivalidad entre dos superpotencias que pretendían la división del planeta en dos esferas de influencia. Tiene en su haber un gran esfuerzo educativo y de salud en su propio pueblo, acompañado de un desarrollo notable de la ciencia y la práctica médica y de un notable fomento del cine autóctono, de la literatura y de las artes plásticas; una gran solidaridad con muchos pueblos pobres del mundo, que se han beneficiado del trabajo voluntario de miles de maestros y médicos cubanos de ambos sexos, presentes hasta en lugares muy remotos de nuestros países, a donde los profesionales de la educación y la salud rara vez llegaron. Y también un ejemplo de dignidad nacional frente al coloso que hacía guardia a noventa millas de la costa de Cuba. Tiene en su debe la incapacidad de haber desarrollado una economía productiva de abastecimiento suficiente y de calidad durante los 30 años (1961-1991) en que gozó de un intercambio comercial privilegiado con la Unión Soviética y de una inversión tecnológica de cierta calidad proveniente de ese país. Y también haber hecho de la isla un lugar de aislamiento respecto del mundo no socialista, haberse mostrado incapaz de desarrollar una comunicación creativa de prensa, radio y televisión, haber sido incapaz de ofrecer tolerancia para la disidencia, libertad de emigración sin estigmatizar a los emigrados, y una democracia verdaderamente eficaz con opción política entre candidaturas, aunque solo fuera de propuestas diferentes dentro del proyecto socialista. Al final, se ha convertido en una gerontocracia, donde los iniciadores de la revolución, cargados de años, han ido devorando todas las posibilidades internas de relevo generacional.

\section{La revolución en libertad chilena}

La revolución en libertad, de Salvador Allende, sufrió desde sus primeros pasos tanto el cerco implacable del gran capital chileno como la enfermedad incurable del divisionismo mutuamente intransigente de la Coalición de izquierda que ganó una oportunidad histórica. La huelga de abastecimiento del comercio dominado por las clases medias altas, la conspiración de los Estados Unidos de Norteamérica a través del secretario de Estado del presidente Richard Nixon, el Dr. Henry Kissinger, confesada por ambos en sus papeles hoy públicos, y la vo- 
rágine de radicalismo de los movimientos de izquierda más "infantiles" - habría dicho Lenin -, es decir, menos maduros, y el apartamiento de la jefatura de las Fuerzas Armadas de militares comprometidos con el constitucionalismo democrático, condujeron, como casi elementos de una tragedia griega, al golpe de Estado de Augusto Pinochet, nunca tal vez mejor dibujado en su carácter antihumano que con la destrucción de las manos y los dedos y luego de la vida misma, del guitarrista y cantautor Víctor Jara en los sótanos del Estadio Nacional de Santiago, convertido en prisión multitudinaria. Ni el impulso al desarrollo económico liderado por los Chicago Boys del economista neoliberal Milton Friedman puede hacer olvidar, y mucho menos justificar, el golpe militar, la drástica supresión de las libertades ciudadanas, las prisiones, torturas y asesinatos de opositores (incluso de militares constitucionalistas demócratas, como el padre de la actual presidenta de Chile, el general Bachelet), y la imposición de un pensamiento y una voz únicos. La resistencia al golpe y a la dictadura fraguó en 1988 con la derrota en las urnas de la opción plebiscitaria de Augusto Pinochet y de su nueva Constitución. En los años subsiguientes, demócratas coaligados en una centro-izquierda, han ganado las elecciones cuatro veces consecutivas, han acabado por suprimir legalmente los condicionamientos a la democracia impuestos por el anciano ex dictador y llegaron a ser testigos del profundo desprestigio de este mismo y de su familia al haber sido llevados a los tribunales por una acusación de un acto tan poco heroico como la apropiación corrupta e indebida de fondos del Estado. Hasta el momento actual ningún otro Jefe de Estado demócrata en América Latina ha obtenido al final de su mandato un porcentaje de aprobación tan elevado como el del tercer presidente electo por la Coalición centro-izquierda, Ricardo Lagos: un $70 \%$.

\section{La revolución sandinista en Nicaragua}

La Revolución sandinista en Nicaragua levantó durante diez años las esperanzas de los pobres en América Latina. Habiendo tenido lugar también durante la Guerra Fría y además en el recrudecimiento de ésta liderado por el presidente Reagan (1981-1989) con su "Guerra de las Galaxias", se hizo clásica la imagen del pequeño David luchando para defenderse del gigante Goliat. La pequeña Nicaragua y su pueblo tenaz contra los grandes Estados Unidos y su presidente neoliberal y neoconservador, protector de los "Luchadores por la Libertad". Con estos últimos quería Reagan - "el Gran Comunicador" - dar un carácter de héroes a los que hacían la contrarrevolución desde las plataformas de Honduras, equiparándolos con los que en las Trece Colonias de la costa atlántica lucharon por la libertad en el siglo XVIII para formar los Estados Unidos de Norteamérica y su independencia del Imperio inglés. El 25 de enero de 1990, Daniel Ortega, presidente de la Nicaragua sandinista, y Sergio Ramírez, candidato a la vicepresidencia, fueron derrotados en las urnas por la Unión Nacional Opositora $(\mathrm{UNO})$ que llevó como candidata a la viuda del periodista asesinado Pedro 
Joaquín Chamorro, Violeta Barrios. En el haber de la Revolución sandinista hay que contar la victoria contra la dictadura somocista que, con una operación dinástica y un apoyo casi incondicional de los diversos gobiernos estadounidenses desde Franklin Roosevelt hasta Gerald Ford (1932-1976) y un dominio absoluto sobre la Guardia Nacional, había enriquecido a la familia gobernante y a sus allegados y había perseguido y, sobre todo, dividido a sus opositores, e incluso pactado con ellos corroyendo y corrompiendo sus posiciones patrióticas. Hay que contar también la reforma agraria, la Cruzada Nacional de Alfabetización que despertó la capacidad para el sacrificio generoso en una juventud llena de expectativas y esperanzas, la dedicación a los pobres de la capital y su organización nacional, el esfuerzo por poner bases para un desarrollo agroindustrial e industrial del país, la heroica defensa del proceso revolucionario frente a la intervención flagrante de los Estados Unidos, que llegaron a negociar clandestinamente armas para la contrarrevolución incluso con un gobierno tan hostil a ellos como el del Irán del ayatolá Jomeini, y el sometimiento de la revolución a la voluntad popular en dos elecciones democráticas y libres, una ganada y otra perdida. En su debe hay que contar la alineación con el bloque soviético, la dependencia del modelo cubano de gobierno y de desarrollo con lo que implicaba de falta de creatividad de un modelo político-económico novedoso, la confianza en las armas y en la guerra más que en la incorporación madura y responsable de la población a tareas revolucionarias de desarrollo, el antagonismo de muchos dirigentes revolucionarios urbanos con la población campesina que hizo que la contrarrevolución pudiera apoyar su lucha intervencionista en el descontento campesino y generar incluso una guerra de campesinos contra el gobierno nacional revolucionario, los rasgos dictatoriales presentes en la requisa de la producción alimentaria campesina para armar una distribución que contribuyera al dominio estatal del comercio de recursos de primera necesidad. Y sobre todo la apropiación por dirigentes del partido sandinista de bienes del Estado y del pueblo en el período entre la derrota electoral y la toma de posesión de Violeta Barrios. Pero lo peor estaba por venir. Sin aceptar el dictamen ético de una comisión del mismo FSLN, lo cual llevó a la renuncia del partido de Ernesto y Fernando Cardenal y del mismo Henry Ruiz, y se concretó con el pacto entre el FSLN liderado por Daniel Ortega y el Partido Liberal de Arnoldo Alemán. En la peor tradición somocista de pactos, el FSLN se aseguró así tanto su mayor peso en el Tribunal Supremo Electoral como en la Corte Suprema de Justicia y de tribunales inferiores, y el compartir del Parlamento entre ambos partidos. Al mismo tiempo el sandinismo se volvió orteguismo o danielismo al impedir cualquier tipo de relevo en la cúpula del FSLN y cancelar además con un típico truco de los tiempos somocistas la personalidad jurídica del partido Movimiento Renovador Sandinista, con algunos de los más famosos disidentes del FSLN, como los ex comandantes de la Revolución Henry Ruiz ("Modesto") y Víctor Tirado y la ex comandante guerrillera Dora María Téllez. Y al comprar al par- 
tido disidente del Liberal, liderado por Eduardo Montealegre, quien se atrevió a desafiar el liderazgo de Alemán. El resultado hoy es una revolución transformada en patrimonio familiar de la pareja presidencial, Daniel Ortega y Rosario Murillo, y de sus numerosos vástagos, y el rechazo de Daniel por movimientos feministas latinoamericanos, que querrían ver que se sometiese a la justicia por haber abusado de una hija de su mujer durante muchos años. Por otra parte, sigue siendo multitudinaria la emigración a Costa Rica.

\section{Los acuerdos de paz en Guatemala}

Los acuerdos de paz en Guatemala, firmados el 29 de diciembre de 1996, después de 36 años de conflicto armado interno (1960-1996) y de 200 mil víctimas de las que hay testificación en el Informe de la Comisión para el Esclarecimiento Histórico Guatemala: Memoria del Silencio, constituyeron un auténtico programa de desarrollo económico, de democratización política, de respeto a los derechos humanos, de respeto por el pluralismo cultural, étnico y lingüístico del país, y no contienen ninguna ley de punto final, puesto que de la amnistía contenida en la Ley de Reconciliación están excluidos los delitos de genocidio, de desapariciones forzadas, de tortura y cualesquiera otros crímenes contra la humanidad. Sin embargo, el Estado continúa siendo profundamente débil para el desarrollo, puesto que la carga tributaria no llega al $11 \%$ (los acuerdos de paz programaban alcanzar el $12 \%$ en 4 años) con lo cual los presupuestos de inversión social están severamente limitados. La cultura de la violencia que legó el conflicto armado interno no ha sido superada; al contrario, se ha profundizado por las vinculaciones de antiguos protagonistas militares y de pandillas juveniles - maras - con el crimen organizado, en especial el narcotráfico. La impunidad se ha hecho endémica, tanto por la intermitencia e inconstancia de los esfuerzos para mejorar la Policía Nacional Civil (PNC), como por la corrupción en la Fiscalía General de la República (FGR) y en los tribunales de justicia, aunque la presencia desde hace dos años de la Comisión Internacional contra la Impunidad en Guatemala (CICIG) ha levantado las expectativas de enfrentar en los tribunales casos especialmente ejemplares. Finalmente, la desigualdad en la distribución de la riqueza sigue siendo una de las más grandes del mundo, aunque el PIB haya tenido algunos años de crecimiento constante. Por otro lado, la fuerza de la antigua guerrilla convertida en partido político de izquierda ha disminuido notablemente y la Unidad Revolucionaria Nacional Guatemalteca (URNG) ha dejado por ahora de ser alternativa política. El carácter tímidamente socialdemócrata del actual Gobierno promueve conspiraciones en su contra y su aceptación en los sondeos de opinión pública no llega al $50 \%$, aunque ha ido ascendiendo. También desde Guatemala la emigración hacia los Estados Unidos ha ido en constante ascenso hasta la irrupción de la crisis de la globalización. 


\section{El socialismo del siglo XXI}

Sobre este tema escribí ya anteriormente ${ }^{1}$. Aquí incorporo lo que entonces comenté. Otra corriente importante hoy, especialmente en América Latina, es la del "Socialismo del Siglo XXI". Ha sido hecha famosa por el actual presidente de la República Bolivariana de Venezuela, Hugo Chávez Frías. Según varias fuentes, Chávez habló por primera vez del Socialismo del Siglo XXI en 2005, seis años después de haber sido electo presidente en 1999, y lo hizo en el V Foro Social Mundial, que tuvo lugar en Porto Alegre, Brasil. Más tarde, en un discurso a mediados de 2006, lo definió vagamente así: "Hemos asumido el compromiso de dirigir la Revolución bolivariana hacia el socialismo y contribuir a la senda del socialismo, un socialismo del siglo XXI que se basa en la solidaridad, en la fraternidad, en el amor, en la libertad y en la igualdad". Chávez advirtió que "debemos transformar el modo de capital y avanzar hacia un nuevo socialismo que se debe construir cada día", lo cual añade a la vaguedad porque no sabemos si quiere decir "el modelo capitalista" en general o "el modo actual de funcionar del capital". Lo que sí está claro es que Chávez piensa en una revolución permanente, al estilo del marxismo trotskista. Por eso habla también de fases en el proceso y explícitamente de una fase llamada "democracia revolucionaria", en la que se estaría actualmente en Venezuela.

La vaguedad a que hemos aludido atañe a la falta de un programa detallado, pero no quiere expresar necesariamente una negatividad. Todas las corrientes filosófico-políticas comenzaron con lemas de este tipo: el liberalismo manchesteriano de Adam Smith con "la mano invisible" que hace justicia a todos en el mercado; el republicanismo burgués revolucionario con la proclama de "libertad, igualdad, fraternidad"; el socialismo marxista con "proletarios del mundo, únanse" o "de todos según sus capacidades a todos según sus necesidades"; el keynesianismo con la restauración de los equilibrios del mercado por "la ingeniería económica y social del Estado"; y el neoliberalismo con la economía del "favorecer a la oferta" y el principio de que "gobernar menos es gobernar mejor".

Chávez ha tratado de comenzar la construcción "cada día" del socialismo del siglo XXI con acciones de política social llamadas "V Foro Social Mundial", de las cuales las más conocidas son "Barrio Adentro", dedicada a mejorar la

1. J. Hernández Pico, S.J., en Diakonía.

2. No es Chávez el inventor de este concepto. Su fundador es Heinz Dieterich Steffan, de la Nueva Escuela de Sociología de Bremen, en Alemania, que aplica conceptos de cibernética, mecánica cuántica y el "principio de equivalencia" a la sociología. Desde hace tiempo es profesor en la UNAM de México. Su libro El Socialismo del Siglo XXI (1996) propone un modelo teórico-práctico que "se sustenta en cuatro ejes: el desarrollismo democrático regional, la economía de las equivalencias, la democracia participativa y las comunidades creativas" (ver en la Web "El Socialismo del Siglo XXI", Wikipedia). 
salud popular; "Robinson", dedicada a combatir el analfabetismo y favorecer la educación de adultos; y "Negra Hipólita", dedicada a reintegrar a la sociedad a personas abandonadas y supermarginadas. Pretende que el referéndum del 15 de febrero de 2009, además de permitirle constitucionalmente reelegirse indefinidamente, consagre la incorporación a la Constitución de las "misiones". Chávez se inspira en una triple fuente que llama "el 'árbol de las tres raíces', que es la fuente ideológica. Consiste en la raíz bolivariana (su planteamiento de igualdad y libertad, y su visión geopolítica de integración de América Latina); la raíz zamorana (por Ezequiel Zamora, el general del pueblo soberano y de la unidad cívico-militar); y la raíz robinsoniana (por Simón Rodríguez, el maestro de Bolívar, el Robinson, el sabio de la educación popular, la libertad y la igualdad). Este 'árbol de las tres raíces' da sustancia ideológica al movimiento revolucionario y al Socialismo del siglo XXI"4 . Chávez, por otro lado apela también a las raíces del socialismo en el cristianismo y en sus fuentes vetero y neotestamentarias.

Dada la polarización alrededor del proyecto chavista, pienso que es importante encontrar algunos criterios sólidos para valorar el proyecto chavista. Estos son - revisados - los que expuse en otro trabajo anterior:

Desde el punto de vista material, es decir, desde la perspectiva de la miseria y la pobreza y las necesidades que hacen brotar, la historia valorará positivamente al gobierno del Presidente Chávez si invierte los enormes recursos obtenidos con la renta del petróleo en los últimos años, en la producción inteligente de cambios estructurales económicos a largo plazo, por ejemplo en mejorar tecnológicamente las técnicas de extracción, refinación y derivación petroquímica del crudo, así como de comercialización de los productos refinados y derivados petroquímicamente, y en volver a Venezuela autónoma agrícola y ganaderamente, afianzando la seguridad alimentaria y elevando, a la vez, la base educativa y de salud de ese país, y en crear empleo en obras infraestructurales de interés reproductivo para la economía del país. No en vano Rafael Correa, presidente de Ecuador, acaba de afirmar que "el socialismo debe ser sinónimo de justicia, pero también de eficiencia". [En "Correa: 'América Latina no tiene tiempo que perder en su proceso de integración'”, El País, miércoles 4 de febrero de 2009].

La historia lo valorará negativamente si esos enormes recursos de los que dispone son invertidos únicamente en responder a corto plazo a las necesidades inmediatas de la población empobrecida y excluida. Entonces habrá entregado populistamente pan para hoy y hambre para mañana. Todo esto, desde la perspectiva material.

3. La negra Hipólita fue la nodriza del Libertador Simón Bolívar.

4. A. A. León Field, El Socialismo del Siglo XXI, en la Web, bajo el epígrafe "Socialismo del Siglo XXI". 
Pero queda pendiente la perspectiva de la construcción democrática en libertad del proyecto socialista, atendiendo no sólo a la mayoría que ha apoyado en las urnas al presidente Chávez y lo ha elegido presidente y aprobado los cambios constitucionales propuestos por él (sin entrar en la polémica de si estas elecciones plebiscitarias son legítimas o no por el hecho del abuso de los recursos del Estado para apoyar las posiciones chavistas publicitándolas por medios masivos de comunicación estatales, o incluso con programas fraudulentos de conteo electrónico de los resultados), sino también escuchando los puntos de vista de la minoría y sopesándolos y discerniéndolos con honestidad sin estigmatizarlos como conspiradores. Ese fue el mensaje del 2 de diciembre de 2007 , cuando una leve mayoría opositora a la propuesta de cambios constitucionales del presidente Chávez ganó el referendo y derrotó por el momento esa misma propuesta. Era la primera vez que Chávez perdía en las urnas. Al fin y al cabo la democracia es el sistema de gobierno de todos, por todos, para todos y con todos. Un sistema en el que las mayorías electorales deben gobernar sin desdeñar los puntos de vista de las minorías que pierden las elecciones, sino integrándolos, para que la nación no se desintegre dividiéndose con intransigencia mutua. Los populismos, con sus pinceladas teatrales, no suelen ser unificadores de los puntos de vista legítimamente diversos. Eso es precisamente lo que vimos en el discurso con el que Chávez celebró la victoria del sí por ocho puntos porcentuales en el segundo referéndum sobre cambios constitucionales, que le permitirá postularse a la Presidencia indefinidamente. ${ }^{5}$

Evidentemente, el acoso judicial al Gobernador del Estado de Zulia, Manuel Rosales, uno de los personeros más importantes de la oposición al chavismo, hasta forzar su autoexpatriación y su exilio y asilo en Perú, y posteriormente la nulificación en la práctica de la elección popular del alcalde mayor de Caracas interviniendo su gobierno municipal con un representante del Ejecutivo, plantean serias heridas de la democracia. Otra cosa es la reciente ley de expropiación y de acceso a formas cada vez más invasoras de propiedad estatal, aunque se mantiene todavía la indemnización a los expropiados.

Tanto Correa como Chávez y Evo Morales, del que hablaremos a continuación, seguirán buscando su reelección según las Constituciones nuevas o renovadas que han logrado que el pueblo vote mayoritariamente. Esto, en abstracto o en teoría, no debería asustarnos tanto. Al fin y al cabo, en Inglaterra, Francia, Alemania, Italia o España no hay límites o plazos para la reelección de primeros ministros, presidentes de la República o cancilleres. Nosotros en América Latina

5. J. Hernández Pico, S.J., La insoportable frustración de las expectativas: La presidencia neoliberal globalizada de Óscar Berger (2004-2008), Guatemala, Editorial de Ciencias Sociales, 2008, p. 247. 
dependemos más, sin embargo, de la tradición democrática estadounidense que, después de los cuatro períodos para los que fue electo sucesivamente Franklin Roosevelt, introdujo una enmienda a la Constitución limitando a dos períodos sucesivos la duración de sus presidentes. La propia tradición caudillista y dictatorial latinoamericana, donde el PRI fue Gobierno durante 70 años en México, donde los militares gobernaron 20 años en Brasil (1964-1984) y 17 años en Chile (1973-1990) o donde dictadores como Estrada Cabrera y Ubico en Guatemala se hicieron "reelegir" por 22 ó 13 años, respectivamente, y durante 50 años en Cuba, hace que aquí se desconfíe profundamente de las posibilidades constitucionales de reelección indefinida que son tan normales en Europa.

\section{El proyecto de reconciliación interétnica e intercultural de Evo Morales}

Existe también en América Latina un proyecto político, el de Evo Morales en Bolivia, centrado en el rescate y la devolución a los pueblos indoamericanos de su protagonismo social y político. Ese proyecto intenta empezar a saldar la enorme deuda étnico-cultural y social que varios Estados de América Latina, por ejemplo, Guatemala, Ecuador, Perú, Paraguay y México, entre los más importantes, mantienen con los pueblos indígenas. Esta deuda de desigualdad, opresión, miseria y desprecio es cuantitativamente enorme en esos países. Pero no lo es menor cualitativamente en países como Brasil, Chile o Colombia. El proyecto de Evo, en este sentido, es objetivamente reconciliador y se parece de alguna manera al de Nelson Mandela en Sudáfrica, aunque no tenga Evo el carisma de reconciliación y la aguda visión de soluciones a los problemas del mismo Mandela, y a causa de eso pueda ser a veces un proyecto subjetivamente divisivo. Sin embargo, el proyecto de Evo no ha querido dejar por fuera a criollos y mestizos, como lo muestra simbólicamente el hecho de que su vicepresidente, Álvaro García Linera, sea uno de ellos. Evo también camina con su proyecto hacia un cierto socialismo, si por socialismo se puede entender un Estado fuerte con participación importante en los recursos más cruciales del país, los energéti$\cos$, que asegure su redistribución más simétrica para todas las regiones del país, y también un límite a la posesión individual de la tierra - cinco mil hectáreas-.

Pero sobre todo se encamina Evo hacia una integración latinoamericana, que, como acaba de decir Rafael Correa, no puede ya esperar un minuto más, pues sin aprovechar esta hora histórica para su integración regional, América Latina quedará sin capacidad de negociación global. Evo Morales se ha integrado ya en la Alianza Bolivariana para las Américas (ALBA), con Venezuela, Cuba, Nicaragua, Honduras y Dominica, y en la Unión de Naciones Suramericanas (UNASUR), creada en 2008, cuya sede será en Quito, aunque temporalmente esté en Brasilia, y cuya primer presidenta por un año será Michelle Bachelet, de Chile. UNASUR envió ya una delegación para investigar las muertes violentas en el departamento de Pando, en Bolivia, con ocasión del referéndum que rati- 
ficó a Evo Morales como presidente; esa delegación hizo un trabajo rápido que terminó con el resultado de responsabilizar al gobernador de Pando de dichas muertes. El proyecto de Evo choca con la oposición intransigente de los departamentos de la "Media Luna" (Beni, Pando, Santa Cruz y Tarija), sede de las explotaciones más importantes de gas natural e hidrocarburos y, en el caso de Santa Cruz, de las haciendas más grandes de soya. Estos departamentos reclaman una autonomía especial, superior a la que les da la nueva Constitución, y un uso privilegiado de los ingresos provenientes del gas natural y de los hidrocarburos, mientras que la nueva Constitución indica que esos ingresos han de servir a todo el país equitativamente. El resultado del referéndum del 25 de enero de 2009 fue favorable a la nueva Constitución (en números redondos 61-39\%). En cualquier otro caso este porcentaje favorable habría sido un éxito importante, pero no así en el caso de Bolivia, donde el "no" ganó en la "Media Luna" por porcentajes de alrededor de $70 \%$, dejando al país profundamente dividido.

\section{La izquierda latinoamericana socialdemócrata}

Los proyectos políticos de los dos últimos presidentes de Argentina, Néstor Kirchner y Cristina Fernández de Kirchner, peronistas de izquierda, y de Fernando Lugo, primer presidente del Partido Liberal en Paraguay desde 2008 -el Partido Colorado había gobernado antes por más de 60 años-, tienden a cierta simpatía con los proyectos de Ecuador, Venezuela y Bolivia, y a una apertura clara a Cuba.

En cambio, los proyectos políticos de izquierda de la Concertación de Partidos por la Democracia en Chile (desde 1990 hasta hoy) con sus presidentes, Patricio Aylwin, Eduardo Frei, Ricardo Lagos y Michelle Bachelet; del Partido de los Trabajadores (PT) en Brasil (2003 hasta hoy), con su presidente Luiz Inácio "Lula" da Silva; y del Frente Amplio, en coalición con otras dos agrupaciones políticas de izquierda, en Uruguay, con la victoria en 2004 de Tabaré Vázquez, pasan por ser proyectos más socialdemócratas. Tienen el récord de popularidad para algunos de ellos; por ejemplo, ya hemos dicho que Ricardo Lagos terminó su mandato de 6 años con un $70 \%$ de aprobación, y Lula acaba de terminar su sexto año (de ocho) con un $80 \%$ de aprobación, a pesar de las evidencias de corrupción en el PT, que han obligado a renunciar a varios de sus ministros. Los proyectos "Hambre Cero" y "Bolsa Familia", del Gobierno de Lula, han sacado de la pobreza a alrededor de 20 millones de personas, y eso aunque para algunos de los amigos más cercanos de toda la vida de Lula, como Frei Betto, su gobierno merece críticas tan serias como para haberse decidido a renunciar de liderar el programa "Hambre Cero". Probablemente es Lula hoy el dirigente político latinoamericano con mayor prestigio no sólo en América Latina, sino a nivel mundial. A pesar de sus programas de socialismo moderado -o tal vez precisamente por ellos - su presencia en los foros sociales mundiales es acogida 
con gran simpatía. Y al mismo tiempo puede viajar a Davos y ser escuchado con respeto.

\section{Una apuesta absoluta por proyectos relativos surcados de fracasos}

En este contexto hemos de ver la victoria de la izquierda en El Salvador. Todos los acontecimientos políticos que hemos ido estudiando son proyectos humanos grupales, que de un modo u otro, han querido, cuando se crearon, abrir cauces para un mundo más justo. Todos ellos tuvieron en el centro de sus programas un profundo amor por los pobres, que en estos países nuestros de América Latina son mayorías. Todos ellos en un momento dado merecieron que se les diera un apoyo absoluto, porque eran apuestas históricas contra la desigualdad, la discriminación, la miseria, la pobreza, la corrupción, el abuso de poder, la acumulación de riqueza sin límites, la violación de los derechos humanos, el monopolio y la distorsión de la información, la tortura y otros crímenes de lesa humanidad, la pudrición de la democracia ${ }^{6}$. Obviamente, estaban todos ellos amenazados de desvíos, de esa tremenda maldición que consiste en repetir los mismos errores e incluso las mismas barbaridades inhumanas, contra las cuales lucharon esforzadamente. Todos ellos estaban en último término amenazados de mesianismo. No en el sentido bíblico que implica la llegada y el reconocimiento de un líder carismático, profundamente obediente al proyecto creador de Dios y enteramente recreativo de las condiciones sociales de la convivencia humana, alguien que sea una buena noticia para los pobres, y bajo cuyo liderazgo los agricultores siembren para comer y beber de los frutos de su trabajo, y los constructores construyan casas para poder habitarlas, y la riqueza se redistribuya con honradez y equilibrio; alguien dispuesto a servir y a entregar la propia vida en el camino de ese servicio. Sino en el sentido político que implica la conversión de los administradores de los recursos de la tierra y de los medios de producción, del orden social y de los valores culturales en "señor", en "patriarca", en "conductor", en "caudillo", o en "jefe", a últimas de cambio en alguien vuelto "ído1o", ante quien el país, la región o la humanidad deben postrarse para venerarlo y adorarlo como oráculo infalible de bienestar y dominio.

\section{La pregunta angustiada: ¿nada cambia en la historia y en el mundo?}

Sin embargo, esta gran amenaza que acecha a todo proyecto político, especialmente de izquierda, no anula el valor de diseñar tales proyectos ni el de intentar llevarlos a la práctica. Se puede apostar por lo amenazado, relativo y deficiente con una dedicación y un entusiasmo absolutos. Esperando que la fascinación de la lucha por la justicia supere a la desilusión por la empecinada y

6. Así como de "pudrición de la democracia" ha escrito el notable sociólogo guatemalteco con vínculos en casi toda Centroamérica, Edelberto Torres Rivas. 
continua emergencia de la injusticia. Vivimos en un mundo en el que el deseo de mejorar la distribución del bienestar para todos se trunca y frustra una y otra vez porque no cambia la condición humana. La meta del "hombre nuevo" $-\mathrm{y}$ hoy habría que añadir la de la "mujer nueva" - se muestra una y otra vez inaccesible. Y la pregunta angustiada o desilusionada emerge con fuerza invencible: ¿para qué seguir comprometiéndose en la política si la esperanza se ve frustrada continuamente?

\section{¿Pasó algo nuevo el 15 de marzo de 2009 en El Salvador?}

¿Pasó algo nuevo el 15 de marzo de 2009 cuando un $51.32 \%$ de los votos emitidos en El Salvador se decantó por Mauricio Funes y el FMLN? Con su sencillez campesina, un habitante de Arcatao, en el norte de Chalatenango, de alrededor de 60 años y sobreviviente primero de la guerra y luego del cáncer, lo expresó bien con una mirada de júbilo: "Hemos conseguido al fin lo que hemos estado esperando durante 20 años". La esperanza de los pobres encontró al fin una respuesta a sus anhelos. Él y sus compañeros fueron los de las "guindas", los que dejaron atrás sus comunidades y se atrevieron con los barrancos de su terruño para escapar de la tierra arrasada y de la persecución con masacre que los esperaba a manos del Ejército en los márgenes del río Sumpul o en cantones como El Mozote. En esos barrancos se escondieron, se movieron solo de noche para buscar alimentos, escapando del Batallón Atlacatl y de coroneles como Monterrosa que servían a los intereses de las que en un tiempo se denominaron Las Catorce Familias dueñas de El Salvador. Ellos y ellas, familias enteras, pueblos completos, tenían puesta su esperanza en un proyecto nuevo de libertad y de justicia. Incluso con los Acuerdos de Paz en 1992, pareció que nunca iba a venir la posibilidad de un gobierno para los pobres. Sin embargo, el 15 de marzo se vio que, como esperaba Ignacio Ellacuría, "el pueblo salvadoreño había reflexionado en sus comunidades de base desde un punto de vista eclesial, en sus cantones y municipios desde un punto de vista social, y, en resumen, el pueblo salvadoreño había dejado oír su voz" en las urnas.

Veinte años y cuatro Gobiernos derechistas de la Alianza Republicana Nacionalista (Arena) no habían encaminado al país hacia un bienestar más repartido. Después de la firma de la paz, las mismas pocas grandes familias habían privatizado de nuevo el sistema bancario, se habían aprovechado de su información privilegiada desde el Gobierno del presidente Cristiani y habían comprado los grandes bancos Cuscatlán y Agrícola Comercial para las mismas familias de siempre, los Dueñas, los Regalado, los Cristiani y los Baldocchi, los De Sola y los Sol, los Notebohm y los Guirola, etc., y para los nuevos ricos, los Simán y

7. Hablando con justicia, existen algunos miembros de la familia Simán que hace muchos años que favorecen proyectos históricos de izquierda en El Salvador y que tuvieron que sufrir por hacerlo. Tengo por ellos un profundo respeto. 
los Poma, entre otros. Familias, sin embargo, vinculadas con los demás capitales centroamericanos y ya, por su inversión multinacional, globalizadas.

Veinte años y cuatro gobiernos de derecha no habían sido capaces de frenar el desangre de El Salvador hacia los Estados Unidos. Veinte años y cuatro gobiernos de derecha habían hecho que en El Salvador aumentara la pobreza, a pesar de las remesas enviadas por los emigrantes y de la dolarización, y del Tratado de Libre Comercio (TLC) con los Estados Unidos y con el resto de Centroamérica y la República Dominicana. Veinte años y cuatro Gobiernos de derecha habían dejado una cosecha de aumento de la violencia en el país, de brutalidad hacia la juventud de los barrios marginados y de conversión de El Salvador en corredor para el narcotráfico.

\section{Heredarán el mundo: proyectos humanos y fe antropológica}

San Pablo afirma que "por el mérito de la fe" - es decir, por haber confiado en Dios cuando tuvo la experiencia de que, siendo viejo Abraham e infecunda su unión con su esposa Sara (Rom 4, 19), sin embargo Dios le prometió una descendencia inconmensurable, "como las estrellas del cielo y como la arena de la playa" (Gn 22, 17; y ver también 13, 16; 15, 5)-, por esa fe, sería "heredero del mundo" (Rom 4, 13). La herencia, fruto de la promesa, que el Génesis concreta en un hijo, a pesar de la infecundidad y la vejez, y en una descendencia innumerable, Pablo la amplía hasta equipararla al mundo entero. La herencia de Abraham es todo el mundo. Quiere decir que el Abraham creyente de las leyendas patriarcales bíblicas del Génesis, aquel hombre caldeo, emigrado a Palestina, y padre del pueblo hebreo, se vuelve de repente para Pablo, el apóstol de Jesucristo que escribe a los romanos, arquetipo paterno de la humanidad entera. La fe, es decir, la afirmación inquebrantable en que la vida personal y la historia de la humanidad tienen sentido y que vale la pena trabajar para mejorarlas y hacerlas más justas y bondadosas, más compasivas y en general más solidarias y humanas, esta fe antropológica - fe humana en la historia, antes de la pertenencia a cualquier alianza religiosa ( $\operatorname{Rom} 4,10)$ - que diseña proyectos, elabora programas para irlos realizando, los evalúa críticamente y los corrige sobre la marcha, esta es la fe que hereda el mundo ${ }^{8}$. La acción política, el compromiso esperanzado en la política se fundamenta en esta fe que valora los proyectos humanizadores, aunque sabe que pueden fracasar. Es una fe que puede llegar a ser marcada por una alianza religiosa (Rom 4,11 ), es una fe que, en términos cristianos, se fundamenta en el Dios que no se deja vencer por la muerte y que sigue siendo creador de vidas humanas: "Dios, de quien se fio [Abraham], que da vida

8. Para quien conoce su teología, habrá sido ya evidente que nos inspira Juan Luis Segundo, especialmente en El Hombre de Hoy ante Jesús de Nazaret, II, 1, Madrid, Cristiandad, 1982, publicado más tarde como La Historia perdida y recuperada de Jesús de Nazaret, Santander, Sal Terrae, 1991. 
a los muertos y llama a existir lo que no existe" (Rom 4, 17). Abraham se fio de un Dios así mucho antes de que Jesús de Nazaret fuera concebido y naciera a la vida mundanal y de que en ese Jesús de Nazaret "el Verbo se hiciera carne y plantara su carpa entre nosotros" (Jn 1, 14). Abraham trabajó su proyecto humano, proyecto de migración y de guerras para asentarse con sus rebaños en Palestina (Gn 12-14) antes de que esa misteriosa presencia divina se identificara ante él como "el Señor, que te saqué de Ur de los Caldeos para darte posesión de esta tierra" (Gn 15,7). La fe antropológica da valor al proyecto humano de Abraham y la fe religiosa reconoce que la fuerza creadora y vencedora de la muerte de Dios da el sentido último a aquel valor. No es extraño, pues, que, en medio de su resistencia al proyecto antihumano de los nazis, Dietrich Bonhoeffer se atreviera a afirmar que para que nos hagamos hermanos de todas las personas que trabajan por humanizar sus vidas y a los pueblos desde la penumbra de Dios o desde su oscuridad, nosotros los cristianos hemos de tener la audacia de realizar las obras de nuestra fe "como si Dios no existiese". Al fin y al cabo el amor de Dios, que no sólo nos creó, sino que nos hizo creadores, muestra su omnipotencia solamente en los extremos trascendentes de la vida y de la muerte: sacándonos de la nada y resucitándonos de la muerte. Pero en la inmanencia de la historia nos acompaña discretamente con todo su amor y amistad mientras nosotros proyectamos y trabajamos privada y públicamente, familiar y políticamente, pero siempre personalmente, la historia, y en la historia nuestros proyectos.

\section{En nuestros proyectos históricos: colaboradores de Dios, labranza de Dios y construcción de Dios}

Pablo, ya hablando de personas creyentes, expresa también de otras maneras, con ayuda de varias metáforas, el carácter de nuestros proyectos privados y públicos, familiares, sociales y políticos, y siempre profundamente personales. Desde la fe en Dios creador y autor de la salvación, afirma que "nosotros somos colaboradores de Dios", aunque también dice que somos un campo donde Dios siembra y un edificio que Dios construye: somos, dice, "labranza de Dios y construcción de Dios" (1Cor 3, 9-10). O tal vez dice que los apóstoles son "colaboradores de Dios", personas que "plantan y riegan" (1Cor 3,6) la semilla de la fe y que los que escuchan la palabra de los apóstoles son el campo donde aquellos siembran y el edificio que construyen. Pablo, en un momento de su vida fue él mismo "labranza y construcción", campo y edificio donde trabajaron otros, y en concreto el anciano Ananías (Hch 9, 10-18); luego se convirtió él mismo en un "último apóstol" (1Cor 15, 9; y ver también 1Cor 9, 1) o "servidor de la fe" (1Cor 3, 5). El trabajo de los apóstoles, ese servicio de la fe, es como el paradigma de todo trabajo humano y cristiano: siempre es un trabajo de plantación y riego, en la metáfora agrícola, hortícola o jardinera, porque es "Dios quien hace crecer" (1Cor 3, 6), ese discreto y eficaz acompañante de todo proyecto en la vida y en la historia humana. Los cristianos conocemos porque 
hemos creído "escuchando el mensaje del Mesías", es decir, de Jesucristo (Rom $10,17)$. Sabemos que nuestros proyectos privados y públicos son colaboración con Dios, aunque esta colaboración es "según el don de Dios" (ICor 3, 5). Pero incluso si es Dios quien discretamente y de modo no siempre patente y evidente hace crecer nuestro propio proyecto, somos nosotros quienes lo trabajamos y "cada uno recibirá su salario según su trabajo" (ICor 3,8). Y esto vale para el trabajo de los cristianos en la historia y también para el de los no cristianos o no creyentes. Porque existen personas y grupos humanos que no han escuchado nunca el mensaje de Jesucristo. Ellos, creyentes de otras religiones o no creyentes, no saben a nuestro modo cristiano de esa actuante discreción de Dios en la historia, en todo proyecto humano. Pero si Pablo, enfrentándose al misterio de lo que para él aparecía como el misterio del rechazo del mensaje de Jesucristo por parte de sus hermanos judíos, llega a decir que ese rechazo tiene un sentido, que ha existido para que el Evangelio tenga una extensión universal en todos los pueblos y así "su rechazo ha significado la reconciliación del mundo" no judío (Rom 11,15 ), no hay duda de que hay una oferta divina de reconciliación en modos imprevisibles no cristianos para personas de religiones diferentes a la cristiana o no creyentes, bien sean agnósticas o ateas. Lo formuló así el Vaticano II:

Asociado al misterio pascual, configurado con la muerte de Cristo, (el cristiano) llegará, corroborado por la esperanza, a la resurrección. Esto vale no solamente para los cristianos, sino también para todos los hombres de buena voluntad, en cuyo corazón obra la gracia de modo invisible. Cristo murió por todos, y la vocación suprema del hombre es en realidad una sola, es decir, la divina. En consecuencia, debemos creer que el Espíritu Santo ofrece a todos la posibilidad de que, en la forma de sólo Dios conocida, se asocien a este misterio pascual. (GS 22).

\section{La diferente calidad de los proyectos humanos: construir con piedra o con paja}

Sin embargo, siguiendo el modo de pensar de Pablo, los proyectos humanos no tienen todos el mismo valor. Existe un juicio humano sobre ellos que hoy día se pasa contemporáneamente a través de sondeos de opinión pública, realizados con mayor o menor agudeza y precisión técnica y que nos dan la fotografía de ese juicio en un momento dado de la historia misma de los proyectos. Existe otro juicio sobre los proyectos humanos que elaboran historiadores de ambos géneros, bien en forma de historia inmediata o de historia después de años, décadas o incluso siglos, y que conduce a una interpretación de la historia confluyente o divergente. Teológicamente existe también el juicio de Dios. Así como el acompañamiento de Dios a los proyectos humanos ha sido discreto pero eficaz, el juicio de Dios tampoco será exterior a los mismos proyectos y según criterios ajenos a ellos, sino que será un juicio sobre el grado de humanidad de estos proyectos. Pablo lo expresa así: 
Según el don que Dios me ha dado, como arquitecto experto puse el cimiento; otro sigue construyendo. Que cada uno se fije en cómo construye. Nadie puede poner otro cimiento que el ya puesto, que es Jesucristo. Sobre ese cimiento uno coloca oro, otro plata, piedras preciosas, madera, hierba, paja. La obra de cada uno quedará patente, pues el día aquel la mostrará: aparecerá con fuego, y el fuego comprobará la calidad de la obra de cada uno. Si la obra que construyó resiste, recibirá su salario. Si la obra se quema, será castigado, aunque se salvará como quien escapa del fuego. (1Cor 3, 10-15).

Pablo, evidentemente, habla en primer lugar del proyecto cristiano de la evangelización - “Ay de mí si no anuncio la buena noticia!” (ICor 9, 16)-. Está hablando a personas cristianas y, por eso, al comparar ese proyecto con la construcción de un edificio, se compara a sí mismo con un arquitecto experto que puso el cimiento, que en este caso es Jesucristo mismo. Piensa en el crecimiento de ese edificio cristiano que cada persona que fue evangelizada por él tiene que seguir construyendo. Nadie puede cambiar de cimiento. La cuestión está en cómo se sigue construyendo el proyecto de ser cristiano. Y ahí es donde diferencia la calidad del edificio que se va construyendo: unos construyen con solidez y belleza la vida cristiana y otros la construyen con fragilidad y fealdad. Pero el proyecto sólo se acaba con la muerte y es en "el día aquel", cuando de la inmanencia de la vida y la historia humana hayamos pasado a la trascendencia de la eternidad, donde ese mismo paso trascendental mostrará la calidad de la obra que hemos construido. La metáfora del fuego puede ser aplicada al Espíritu de Dios ${ }^{9}$, el mismo Espíritu que dio pasión y valiente franqueza (parresía) al anuncio que los apóstoles hicieron (Hch 2,3) de la Resurrección de Jesús de Nazaret, asesinado en el brutal castigo de la crucifixión por los dirigentes de Israel y del Imperio romano: "a Jesús de Nazaret... a éste... ustedes lo crucificaron... y dieron muerte... A este Jesús lo resucitó Dios" (Hch 22-23.32). En ese Espíritu se construye la vida cristiana, en ese "Espíritu de hijos que nos permite clamar Abba, Padre. [Ese] Espíritu atestigua a nuestro espíritu que somos hijos de Dios. Si somos hijos, también somos herederos: herederos de Dios, coherederos con Cristo..." (Rom 8, 15b-16). Vuelve a resonar aquí el tema de la herencia que veíamos a propósito de Abraham, solo que ya desde la fe en Jesucristo. Pues bien, es evidente que Pablo no habla sólo del proyecto de la evangelización, del que él es protagonista, y del de la maduración de la vida cristiana del que fueron

9. Esta aplicación es, a mi juicio, más verosímil exegéticamente que la que en alguna tradición de la Iglesia ha aplicado este fuego al fuego del purgatorio, como crisol de vidas cristianas después de la muerte. Pues la vida y la historia en sentido cristiano terminan con la muerte, y después de la muerte no hay ya vida temporal evolutiva ni historia que se desarrolla, sino solo la luz del Espíritu de Dios que hace brillar con transparencia innegable en la trascendencia, en la vida eterna, la calidad de la vida ya vivida y de la historia ya edificada de mujeres y hombres, de las hijas y los hijos de Dios. 
protagonistas quienes en las comunidades que luego fueron Iglesias $(1$ Cor 1, 2) crecieron en la vida cristiana. El contexto nos dice que Pablo está hablando también de cualquier proyecto humano, privado o público, familiar, profesional, social o político, porque para Pablo, él mismo y los demás evangelizadores, pero además todo el mundo, es la herencia cristiana como lo fue herencia de Abraham: "Todo es de ustedes, Pablo, Apolo, Cefas, el mundo, la vida y la muerte, el presente y el futuro. Todo es de ustedes...". Naturalmente, en el ambiente cristiano en el que está hablando, Pablo continúa: "ustedes son del Mesías y el Mesías es de Dios" (1Cor 3, 21b-22). La vida y la historia, la vida privada y la participación en lo público, todos los proyectos humanos tienen un valor profundo totalmente real.

\section{Compromiso histórico y esperanza cristiana}

La esperanza y el compromiso humano con la historia se enlazan y vinculan estrechamente. No es fácil su discernimiento ni es siempre el mismo el estado de ánimo con que la esperanza afronta la vida y la historia. Existen, en esta esperanza fraterna y sororal, que se compromete solidariamente con la hermandad solidaria, con la libertad en la justicia, con la igual dignidad de las personas y con la creación de posibilidades para ellas, altos y bajos, grandes logros y grandes fracasos, épocas de mayor aproximación y otras de mayor alejamiento, porque la naturaleza y la historia, la humanidad y su vida privada y pública, están orientadas a la unificación, al bien, a la verdad y a la belleza, y sin embargo están también acosadas desde dentro por la fragmentación hostil, por el mal, por la mentira y la fealdad, en una palabra, por "un misterio de iniquidad..., un poder seductor que... haga creer en la mentira" $(2$ Tes $2,7.11)$, pero en general, para Pablo y para su síntesis maduramente humana, todo ello, "los sufrimientos del tiempo presente" (Rom 8, 18), la mujer y el hombre nuevos, la humanidad nueva, la creación rescatada, el reino en proceso que al final Jesucristo entregará al Padre (1Cor 15, 24), todo, es como una gestación que termina en los dolores de parto y en el dar a luz. Pablo, con audacia, afirma que la maduración de la libertad de las hijas y los hijos de Dios va a llevar un largo proceso de dolores de parto, y lo expresa así:

La creación aguarda expectante a que se revelen los hijos de Dios. La humanidad fue sometida al fracaso, no de grado, sino por imposición de otro; pero con la esperanza de que esa humanidad se emanciparía de la esclavitud de la corrupción para obtener la libertad gloriosa de los hijos de Dios. Sabemos que hasta ahora la creación entera está gimiendo con dolores de parto. Y no solo ella; también nosotros que poseemos las primicias del Espíritu, gemimos por dentro aguardando la condición filial, el rescate de nuestro cuerpo. Con esa esperanza nos han salvado. (Rom 8, 19-24a). 


\section{La casa construida sobre roca}

Otras tradiciones neotestamentarias no paulinas, como la mateana, de estilo tal vez menos profético y más sapiencial, hablan de la casa construida sobre roca, que resiste los vientos huracanados, las tormentas y los sismos. Mateo habla de que a esta casa sólida construida sobre roca por un hombre prudente se parecen quienes "escuchan estas palabras (de Jesús) y las ponen en práctica" (Mt 7, 24-25). Una vez más los proyectos humanos, y sobre todo "la búsqueda de la justicia del reino" (Mt 6,33), dan a la vida humana y a la historia una oportunidad de solidez y maduración, que tienen como centro la confianza que desecha los ídolos de la riqueza (Mt 6, 19-32) y la construcción de la hermandad humana por la reconciliación (Mt 5, 23-24).

\section{El nuevo proyecto de izquierda salvadoreño en el Gobierno a la luz de la esperanza}

El proyecto del Gobierno actual del presidente Funes y del FMLN tendrá en los próximos cinco años una oportunidad de construir con oro y con plata, y sobre todo con piedra y sobre roca, en lugar de con paja. La historia humana está hecha de proyectos cuya solidez la pone a prueba en la democracia el juicio de las mayorías, unas mayorías que en El Salvador son especialmente mayorías pobres. Este proyecto de izquierda accede al gobierno en tiempos económicamente muy difíciles de crisis mundial de la globalización. Accede al Gobierno en tiempos políticamente ambivalentes, donde por un lado se ha podido elegir en los Estados Unidos a un mulato, hijo de un africano negro y de una estadounidense blanca, con una historia de trabajo en comunidades marginadas y un proyecto estructuralmente compasivo, y por otro lado estamos sufriendo el primer golpe de Estado ejecutado por los militares, aunque movido por los civiles, en un país centroamericano desde 1982, año del comienzo de la instauración de Gobiernos democráticos, incluso todavía en medio de la guerra. No es cierto que no haya cambiado nada en estos 27 años. No existen hoy una policía y unos ejércitos en cuyo seno anidan los escuadrones de la muerte. No existen hoy en general desapariciones forzadas y cadáveres torturados en las carreteras. No existen hoy cárceles clandestinas donde se tortura a los sospechosos de izquierdismo. No existen hoy masacres y políticas genocidas de tierra arrasada. No se puede decir que la resistencia civil popular no violenta y la misma lucha armada de las guerrillas, con toda su ambigïedad, no lograron nada. Existe la realidad hoy, en la frágil democracia salvadoreña, de que un partido de izquierda haya llegado al Gobierno y esté tratando de desarrollar un proyecto hacia cierta justicia social. Y esto es ya un avance en la historia. Por esto es que no se puede transigir con un golpe de Estado como el de Honduras, donde los militares asumen nuevamente un poder que no les corresponde en la democracia. 


\section{El diseño y la construcción de una civilización del trabajo y la austeridad}

El proyecto salvadoreño de izquierda con el que se han ganado las elecciones del 15 de marzo de este año parece un proyecto relativamente modesto que no intenta grandes cambios estructurales. Pero ese triunfo electoral puede ser un momento para empezar a sacar a los pobres no solo de la pobreza, sino de la civilización de la riqueza, es decir, del horizonte del consumismo deificado, convertido en ídolo; puede ser el momento de empezar a poner las piedras de una civilización de la austeridad solidaria, que ayude a todos a contribuir a un desarrollo económico sin hacer de los bienes económicos un absoluto, un ídolo ante el cual doblar la rodilla. Este triunfo electoral puede ser una hora para otra historia posible, una historia de solidaridad, una historia de desarrollo espiritual, una civilización también del trabajo en lugar de exclusivamente una civilización del capital. Este triunfo electoral puede ser una hora de lucha contra la codicia. La riqueza no es mala; los bienes de la tierra tienen un destino universal. Mala es la codicia, la pasión por acumular los bienes del país en pocas manos, malos son los abismos insondables entre la remuneración del trabajo y la remuneración del capital, malo es el endiosamiento del dinero. El Nuevo Testamento dice que "la raíz de todos los males es la codicia; por entregarse a ella, algunos se alejaron de la fe y se atormentaron con muchos sufrimientos" (1Tim 6, 10). La pasión de la civilización del capital no produce solamente un problema moral de inhumanidad, sino que lleva en sí intrínsecamente una fuente de sufrimiento. Evidentemente, no se puede tomar esto a la letra con ingenuidad. Existe gente inmensamente rica o bastante rica que vive la vida con una gran despreocupación hacia la pobreza en el mismo mundo donde viven, con un deleite y gozo de la vida aparentemente inagotables e inacabables, con una pasión por la competitividad y el ejercicio de la competencia igualmente insaciables. Pero también para esa gente la vida se acaba y la muerte los deja igualmente desnudos, aunque sea debajo de monumentos funerarios extraordinarios. El horizonte de la muerte puede introducir una pausa reflexiva sobre el sentido de la más abundante de las vidas materiales.

Este triunfo electoral de la izquierda en El Salvador puede ser para el pueblo cristiano una hora de poner la iluminación de la fe al servicio de la inteligencia política, para que la fe oriente la mente hacia soluciones plenamente humanas, como decía el Concilio Vaticano II (GS 11). Este triunfo electoral puede ser una de esas horas en que el pueblo salvadoreño, recuperando la memoria histórica de las víctimas de la defensa a ultranza del capital, busque con libertad política acercarse a la libertad de hijos e hijas de Dios. Puede ser una hora de construir con piedra y sobre roca la búsqueda del acercamiento asintótico a la justicia del reino de Dios. Puede ser una hora de cambio de dioses. En lugar de seguir pagando tributo al dios del enriquecimiento individual, trabajar humanamente para la riqueza solidaria; en lugar de seguir pagando tributo a la especulación 
del capital, trabajar humanamente para la redistribución de la riqueza; en lugar de seguir tolerando la evasión de impuestos, recolectar con pericia y acuciosidad los impuestos para ponerlos al servicio de la inversión social; en lugar de seguir construyendo únicamente autopistas y centros comerciales lujosos, propiciar la red de comunicaciones entre los municipios pobres del país y entre ellos y sus cantones, y el desarrollo de mercados para la economía informal del país.

\section{La esperanza crucificada en los costos de la lucha por la justicia y en sus fracasos}

Los fracasos en las propuestas para el cambio no pueden ser argumento para no seguir luchando por la justicia y tratar de que la historia cambie de dirección. Ya decía el famoso dramaturgo alemán Bertolt Brecht que las personas indispensables son las que luchan toda la vida hasta el final. Y el Nuevo Testamento nos dice que la esperanza se fundamenta en la paciencia porque aquella esperanza que solo intenta ver resultados ya no es esperanza (Rom 8, 24-25). La esperanza con paciencia es una esperanza crucificada, porque sabe los costos humanos de la lucha y nunca se olvida de la injusticia de quienes murieron antes de ver cambiar la historia, bien porque los mataron o porque no tocaron con sus manos lo que en sus mentes diseñaron y en sus corazones esperaron y desearon. La esperanza crucificada es además la esperanza de los mártires de la lucha por la igualdad, la justicia, la libertad y la hermandad. De los mártires que creyeron que vale la pena luchar contra el egoísmo propio y ajeno para acercarnos a la felicidad o a esa patria en la que ninguno hemos estado todavía.

El presidente Funes evocó, en su discurso de celebración del triunfo y en su discurso de toma de posesión, al arzobispo mártir Óscar Arnulfo Romero y a su opción por los pobres y afirmó solemnemente que esa sería también su propia opción. Fueron palabras mayores que no se pronuncian impunemente. Producen expectativas políticas nuevas y diferentes. Pero, aunque no se cumplan y una vez más tengamos que seguir soportando los fracasos de la historia, nosotros los cristianos tendremos que seguir creyendo que los rostros de los hambrientos y sedientos, de los que no tienen ropa que ponerse encima, de los sin techo, de los emigrantes, de los encarcelados, sean presos políticos o criminales, son los rostros sufrientes de Jesucristo, que están esperando que encontrándonos con ellos nos encontremos con el mismo Jesucristo, y que están anhelando que contribuyamos a bajarlos de sus cruces. Así lo expresó Puebla y desde entonces, hace más de 30 años, la Iglesia latinoamericana lo ha profundizado y refrendado. $\mathrm{Si}$ el nuevo proyecto histórico de la izquierda en El Salvador no llega a cuajar y fracasa, los cristianos deberemos seguir en la lucha crucial de nuestro tiempo, la lucha por la fe y la lucha por la justicia que la misma fe exige, y deberemos contribuir, a imagen del Dios que no se olvida de los pobres, a que "la esperanza de los pobres nunca se frustre" totalmente (Sal 9, 19). 